\title{
ARTE MEXICANO EN NUEVA YORK
}

\author{
Pि R \\ W A L T E R P A C H
}

CADA día se nota más en los Estados Unidos la realización del significado que se impone a las palabras "el Nuevo Mundo". Es fácil de explicar esto por la guerra europea, con su amenaza de extender el sistema fascista o totalitarista, más bien, al Continente Americano. Pero es una explicación demasiado fácil, porque olvida los esfuerzos tenaces y pacientes que han consagrado desde hace muchos años los hombres de buena voluntad y de buena inteligencia a la obra de comprensión y de solidaridad entre los paises americanos. $;$

El movimiento que representan estos protagonistas de una América lógica en sus relaciones internas, acaba de recibir una impulsión de las más importantes por varios hechos de artistas mexicanos. Colaborando con el $\mathrm{Mu}$ seo de Arte Moderno en Nueva York, las autoridades mexicanas han dado una exposición que revela como nunca en la historia del mundo, lo inmenso de lo que ha alcanzado México durante veinte siglos. Para millares de norteamericanos, eso ha sido una experiencia única, y que ha de dejar un efecto permanente, sobre todo porque es imposible ignorar la fase esencial de la manifestación: es la continuidad de este arte hasta la hora actual. Como si fuera para dar a la idea una prueba dramática, José Clemente Orozco pintó durante la exposición un fresco cuyo tema rivalizó con los periódicos más 
recientes por su comentario sobre la tragedia que vivinos, mientras que por su comprensión de los elementos eternos en el hombre, siguió con el mensaje de los más antiguos americanos.

Ĺn gran público se dió cuenta de ello, pero quizá no valorizó al igual otro acontecimiento de este verano, $\tan$ notable. En el pabellón mexicano de la Feria Mundial de Nueva York hemos tenido el encanto de ver los bailes de Estela y Ëmma Ruiz. Si pocas personas han hecho menos que reconocer que era, en verdad, un encanto, cabe dudar que muchos hayan comprendido toda la importancia de su arte. Porque las danzas mexicanas ocupan una posición ṕrivilegiada (por lo menos en la interpretación dada por estas dos artistas), entre las supervivencias tradicionales que se encuentran en varios paises europeos $u$ orientales, $y$ los esfuerzos tan interesantes para crear bailes nuevos que hacen ciertos individuos y grupos.

Las señoritas Ruiz demuestran, como los pintores modernos de México, que es posible utilizar la vieja inspiración de la raza, las ideas transmitidas desde muy lejos en los siglos, y aún quedarse dentro de la vida actual. Acaso sea mejor que el público general no haya visto más que una aparición de belleza exótica, colores, trajes, alhajas, cuando las bailarinas ejecutaban sus pasos complicados y sonreian con la seguridad debida a una experiencia más que personal, porque viene del pasado de su familia y de su pais.

Acaso hubiera sido una lástima si todos delante de lo monumental de Estela Ruiz — haciendo su entrada grandiosa para la "zandunga" - hubiesen pensado en la identidad de su gesto y su espiritu con los de la portadora de ofrendas que conocen los estudiantes de arte egipcio en el Louvre y otros museos. ¿Es muy peligroso, eso de los museos! Para los que saben utilizarlos, es decir, los fuertes; son la vida; para los débiles que no pueden resistir a su peso, son la muerte, a causa de la tendencia demasiado general de forzar el exterior del arte a otro exterior, de un periodo clásico. Habiendo estado presente la primera vez que la señorita Ruiz vió la escultura egipcia, estoy perfectamente fundado para decir que su gesto no está estudiado de un modelo antiguo, sino resulta espontáneamente de la naturaleza de su baile. Recreando la jdea de una of renda religiosa, era lógico que se repitiera -aun después de cincuenta siglos- el ritmo de la célebre figura egipcia. i Y cuánto más sencillo es explicar todos los aspectos comunes entre el arte de México y el de ligipto, por razones semejantes, en vez de buscar relacjones por un Atlantis legendario y tan lejos de lo probable!

Como delante de las maravillas toltecas y aztecas expuestas en el Museo de Arte Moderno, la persona un poco sensible reconoce sus inpresiones más fuertes belante del arte dejado por las grandes razas del Viejo Mundo y no 
necesita buscar el por qué, asi nos basta sentir lo magnifico del baile tehuano sin marearse con problemas sobre un contacto posible entre dos artes separados por tanto tiempo y tanto espacio.

Hay que volver siempre a las palabras sencillas como las de un niño o de un sabio -pronunciadas por el divino. Poussin-: "El fin del arte es la delectación". Bueno, pero ¿quién es quien goza? El vulgar, el estúpido llana delectación al sentimiento que recibe de las cosas físicas más triviales o de las obras correspondientes por su calidad baja. Pero el hombre fino, cuando goza, nos da la única prueba posible de la presencia.

Por eso, un norteamericano puede sentir una satisfacción legítinua al presenciar la reacción directa de un público de feria nundial (es decir, de las perșonas que venían a gozar de los bailes en el Pabellón Mexicano). Cada vez que Emma Ruiz presentó "Las Chiapanecas", se manifestó una apreciación igual, los espectadores viniendo muy exactamente con palmas a acentuar el ritino de la música, que interpretaba la joven artista fascinadora en la plataforma.

Empecé hablando de la impulsión dada por los artistas mexicanos a la comprensión entre las naciones anericanas, y el que ha notado lo sólido, lo profundo de la impresión creada en el público de Nueva York por los artistas antiguos y modernos de México, puede decir cuán acertado era Plutarco Elilias Calles cuando dijo en un discurso que "el internacionalismo que tiene una base puramente materialista es mentira". I.o que acabamos de ver es un internacionalismo atténtico y sano.

Octubre de 1940. Nueva York.

\section{* BIBLIOGRAFIA DE WALTER PACH}

LI B R OS

Georges Seurat. 1923.

The Masters of Modern Art. 1924.

R. Duchamp-Villon. 1924.

Ananias or the False Artist. 1928.

Modern Art in America. 1928.

An Hour of Art. 1930.

Queer thing. Painting. 1938. (Octavio Barreda tradujo y publicó en "Letras de México". N9 6, Vol. II, 15 de junio 1939, un fragmento de eate libro, bajo ei titulo de "México").

Ingres. 1939. 


\section{TRADUCCIONES}

Historia del Arte, por Elie Faure (Del francés al inglés). Diario de Eugenio Delactoix

( " . . . . ).

\section{ARTICULOS}

En un númeto aproximado de 150 articulos, hay los siguientet sobre México: "Impresiones sobre el Arte Actual de México". México Modeno. 18 de oct. 1922.

"The Popular Arta of Mexico". The Freeman. Jan. 3 1st. 1923.

"The Greatest American Artista", Harper's Magazine. Jan. 1924.

"Mexican Art and Culture". N. Y. Times. Nov, 30th. 1924.

"Mexican School, Children and Jean Charlot". The Art Center Bulfetin. April. 1926.

“L'Art au Mexique - Les Musées". L'Amodr de L'Arc. Sept. 1926.

“L'Art an Merique - Lea Artistes d'Anjourd'hui'”. L'Amour de L'Art. Marth. 1927. *

"The Evolution of Diego Rivera". Creative Art. Jan. 1929.

'Rockefeller, Rivera and Art'. Harper's Magazine. Sept. 1933.

'New-Found Valves in Ancient America", Parnassus. Dic. 1935.

"The Exhibition of Frida Kahlo". The Art News. Nov. 12th. 1938.

"The Indian as Artist". (Revisión de las Artea Indigenas en Norte América, por George C. Vaillant), The New Republic, May 20th. 1940.

- Estos dos articulos fueron publicados en español en "El Argentino", de La Plata. Dic. 17 a 25 de 1927. 


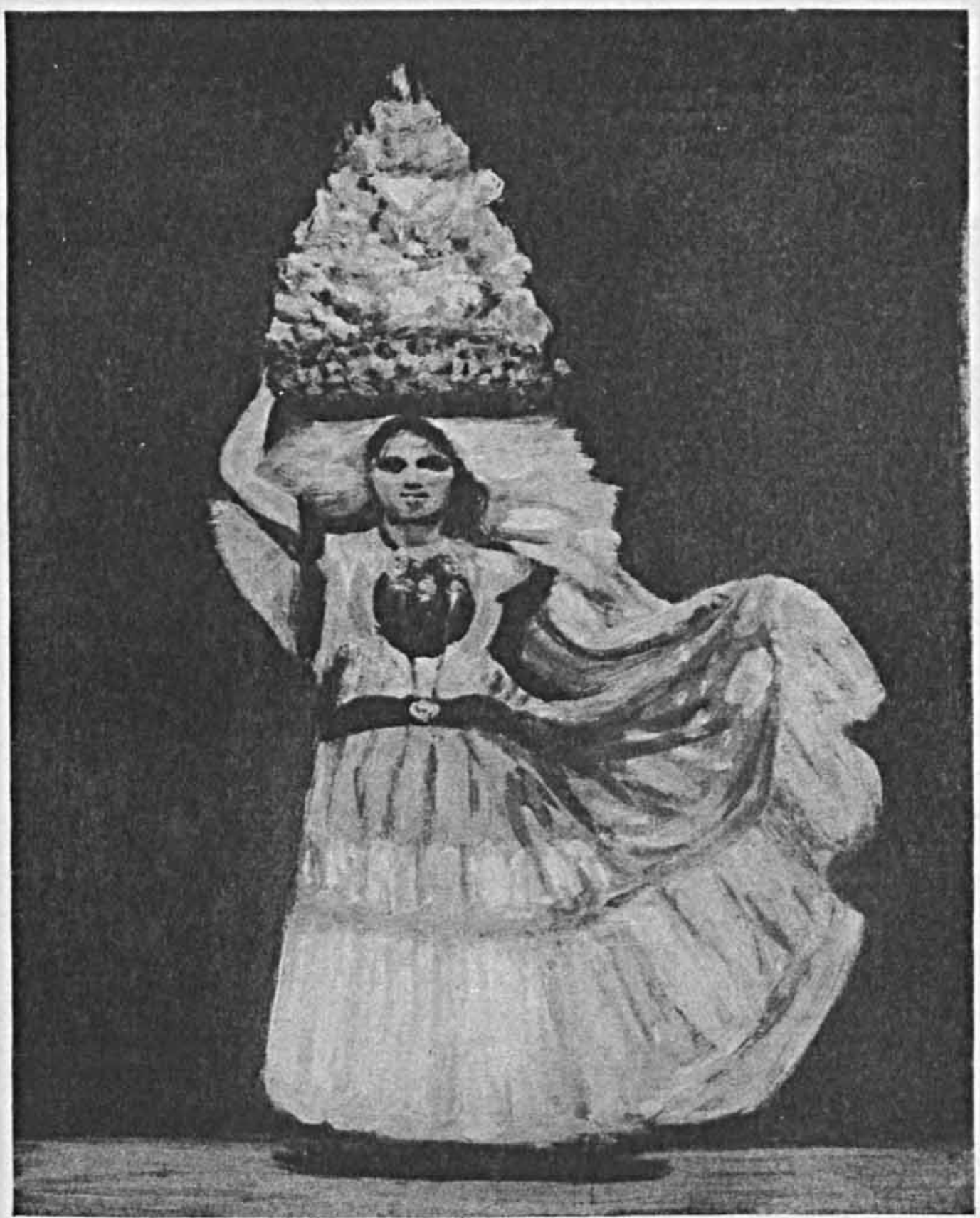

Fig. 1.-La Zandunga. Recuerdo de Estela Ruiz en la Feria Mundial. 1940. Apunte al óleo, de Walter Pach. 